\title{
Economic Growth and Pollution Emission in China: Structural Path Analysis
}

\author{
Na Yang ${ }^{1,2}$, Zilong Zhang ${ }^{1,2,3, *}$, Bing Xue ${ }^{4,5} \mathbb{D}^{-}$, Junxia Ma ${ }^{1,2}$, Xingpeng Chen ${ }^{1,2,3}$ and \\ Chenyu Lu ${ }^{6}$ \\ 1 College of Earth and Environmental Sciences, Lanzhou University, Lanzhou 730000, China; \\ nyang16@lzu.edu.cn (N.Y.); majx2017@lzu.edu.cn (J.M.); chenxp@lzu.edu.cn (X.C.) \\ 2 Research Institute for Circular Economy in Western China, Lanzhou University, Lanzhou 730000, China \\ 3 Key Laboratory of Western China's Environmental Systems (Ministry of Education), Lanzhou University, \\ Lanzhou 730000, China \\ 4 Key Lab of Pollution Ecology and Environmental Engineering, Institute of Applied Ecology, \\ Chinese Academy of Sciences, Shenyang 110016, China; xuebing@iae.ac.cn \\ 5 Institute for Advanced Sustainability Studies (IASS), 14467 Potsdam, Germany \\ 6 College of Earth Geography and Environmental Science, Northwest Normal University, Lanzhou 730000, \\ China; lcy19810507@163.com \\ * Correspondence: zhangzl@lzu.edu.cn; Tel.: +86-931-891-2404
}

Received: 3 July 2018; Accepted: 13 July 2018; Published: 23 July 2018

\begin{abstract}
The relationship between economic growth and environmental pollution has long been a controversial topic. However, simply the detection of the existence of environmental Kuznets curve (EKC) is not enough to understand how economic growth induced environmental pollution. This study investigated the path and mechanism of the effect of economic growth on the emission of two types of environmental pollutants, that is, industrial smoke and dust and sulfur dioxide, by using a structural equation model and a sample of 283 prefecture-level cities in China in 2005 and 2015. The research results show that economic growth exerted both direct and indirect effects on the emission of the two environmental pollutants. In addition to a direct impact through the economic scale effect, economic growth also indirectly impacted the two environmental pollutants emissions through three mediators, that is, industrial structure, technological innovations and environmental regulations. For different pollutants, the effect paths of economic growth on their emission showed both similarities and differences. First, with regards to industrial smoke and dust emissions and sulfur dioxide emissions, the effects of economic growth on the amount of these two emissions through environmental regulations and the industrial structure were negative inhibitory effects and positive promoting effects, respectively. This means that in prefectural-level cities in China, environmental regulation factors have produced some effects in reducing the emissions of these two pollutants while the industrial structure (level of industrialization) can increase the emissions of these two pollutants. However, the effect strength of these two paths shows a gradual weakening. Second, these two paths differ in effect strength and its changes. The positive promoting effects of the industrial structure on pollutant emission are significantly higher than the inhibitory effects of environmental regulation. In addition, our study also found that the direct impact path of economic growth on environmental pollution also passed significance testing, particularly in 2015. This shows that other reasons affect pollutant emission, such as system factors, spatial migration of industries and so forth.
\end{abstract}

Keywords: economic growth; pollutants emission; influence path; structural equation model 


\section{Introduction}

China has become the largest economic body in Asia and the second largest in the world after 40 years of rapid economic growth since the implementation of the reform and opening up policy. The average annual growth rate of China's gross domestic product reached 12\% from 1978 to 2017. China also has the highest fossil energy consumption and is one of the countries with the highest pollution emissions [1]. The emissions of pollutants, such as sulfur dioxide, nitrogen oxides and particulates, are present at a high level in China. China has become one of the most polluted regions in the world [2] and the past 40 years of economic growth have incurred a high cost of environmental pollution. As the two major engines of rapid economic growth, industrialization and urbanization are considered the major reasons for environmental pollution. Urban development has benefited from the rapid growth of industrialization and urbanization has also provided numerous production factors for industrialization. The two engines interact and enhance each other. However, pollutant emissions from industrialization have also made urban regions the most polluted geospatial units.

The Chinese government has implemented various policies and measures to reduce pollutant emissions and to alleviate urban environmental pollution. A reduction of pollutant emissions has been set as a goal in five-year economic growth plans since earlier this century. For instance, the 11th Five-Year Plan proposed to reduce the emissions of sulfur dioxide by $9.96 \%$ by 2010 based on the amount of 25.49 million tons in 2005 [3]. The 13th Five-Year Plan proposes to control total sulfur dioxide emissions to within 15.80million tons by 2020, a 15\% decline from those in 2015 [3]. To achieve these goals, the Chinese government has released rigorous environmental policies, primarily in three aspects: treatment at the end, management during the process and prevention at the source, such as pollution taxes (charges), emission rights trade and policies, to promote the development and use of clean production technologies. The emission reduction goals and the implementation of corresponding policies have transformed the industrial structure and production modes. For instance, the growth of the recycling economy has reduced the emission of traditional pollutants such as $\mathrm{SO}_{2}$ and particulates and has alleviated urban environmental pollution to some extent. However, from the perspective of sustainable development, China still faces enormous environmental pressure. The pollution issue has not been effectively eradiated. More strict pollution treatment goals are still needed. For instance, the 13th Five-Year Plan proposed to reduce energy consumption by $15 \%$ per ten thousand yuan gross domestic product by 2020, as compared with 2015, and to control the total energy consumption to within 5 billion tons of standard coal. The total emissions of chemical oxygen demand, ammonia, sulfur dioxide and nitrogen oxide are proposed to be controlled to within 20.01 million, 2.07 million, 15.80 million and 15.74 million tons, which are declines of $10 \%, 10 \%, 15 \%$ and $15 \%$, respectively, from 2015. In addition, the total emissions of volatile organic compounds are expected to decline by $10 \%$ from the 2015 value [3]. Therefore, an investigation of paths between urban economic growth and pollutant emissions is imperative. This type of research will provide a reference for policy making to ultimately achieve a win-win situation for economic growth and environmental protection.

The relationship between economic growth and environmental pollution has been always a discussion topic in academia. One of the core themes is the environmental Kuznets curve (EKC) hypothesis. Scholars such as Grossman first discovered an inverted U-shaped relationship between economic growth and pollutant emissions-the EKC—-that is, with economic growth, pollutant emissions tend to first increase (corresponding to environmental deterioration) and then decrease (corresponding to the improvement of environmental quality) [4]. Subsequently, a large number of empirical studies have been conducted on the EKC and its shape. Two major environmental indicators have been applied in empirical studies. One is the pollutant emission amount. With the expected increase of environmental quality, the specific pollutants that empirical studies are concerned with have gradually expanded from the traditional sulfur dioxide [5], nitrogen oxides [6] and waste water [7] to greenhouse gases [8] and particulate matter 2.5 (PM2.5) [9]. The other is comprehensive environmental pressure indicators, such as the ecological footprint $[10,11]$ and ecological efficiency $[12,13]$. In addition, with the increase in resource pressure, scholars have started to pay attention to the empirical 
relationship between resource utilization and economic growth, mainly to test whether economic growth has an EKC empirical relationship to land utilization [14], energy consumption [15,16], or water resource consumption [17]. Current research indicates that the EKC hypothesis is only applicable to atmospheric pollutants, in particular, regional pollutants [18]. The current empirical study results of global pollutants, greenhouse gases, comprehensive environmental pressure indicators, or energy consumption do not always support the EKC hypothesis [19]. In fact, different research results have been derived for different pollutants [20]. In addition, research results could be different when different quantitative methods are used [21,22]. Substantial empirical studies have been conducted to investigate the existence of EKC in China, such as those with provinces [23-26] or prefecture-level cities [27] as spatial units, or those with particular regions as research subjects [28,29]. However, no consensus has been reached [30]. Therefore, research on the relationship between economic growth and the environment should take into consideration the properties of particular pollutants [19]. The "black box" of traditional empirical studies also needs to be broken to investigate the path through which economic growth affects environmental quality. Such research will help in the development of targeted policies to achieve continuous economic growth while improving the environmental quality.

In general, current research at national scale focused on the verification of EKC hypothesis in different regions and time periods. In terms of research methods, traditional methods such as single polynomial equations are mostly applied to estimate data [31], which are not able to reveal the mechanism of the impact of economic growth on environmental pollution. A question is how economic growth directly or indirectly affects environmental pollution through industrial structure, technological innovations and environmental regulations. Few studies have been conducted in this regard. Therefore, using a structural equation model and 283 prefecture-level cities in China as a sample, we quantitatively analyzed the path and mechanism through which the economic growth of 2005 and 2015 directly or indirectly affected environmental pollution and we explored the structural causes of environmental pollution. We anticipate that our study will provide a reference for the development of targeted policies to achieve coordinated economic and environmental development.

\section{Materials and Methods}

\subsection{Research Methods}

The study focused on direct and indirect path and mechanism of economic growth affecting Pollutants emission. We used a structural equation model (SEM) to integrate the industrial structure, environmental regulations and technological progress as mediators between economic growth and environmental pollution. Based on the model, we investigated the direct effect of urban economic growth on environmental pollution and the indirect effect through mediators. The SEM is a multivariate statistic that integrates two statistical methods, factor analysis and path analysis. The model involves relationships among dominant variables, latent variables and disturbance or error variables and the direct, indirect, or overall effect of independent variables on dependent variables can be obtained [32]. The SEM can be used to analyze connections among multiple causes and results and relationships among latent variables. It can also be used to simulate the internal logical relationships among multiple factors. The model is a very important multivariate data analysis tool [33]. The SEM includes two major components: (1) a measurement model to reflect the relationships between latent variables and observation indicators; (2) a structural model to reflect the structural relationships among latent variables.

$$
\begin{aligned}
& \mathrm{Y}=\Lambda \mathrm{y} \eta+\varepsilon \\
& \mathrm{X}=\Lambda \mathrm{x} \xi+\delta
\end{aligned}
$$

where $\varepsilon$ is not correlated with $\eta, \xi$, or $\delta . \delta$ is not correlated with $\eta, \xi$, or $\varepsilon$. $\Lambda$ x and $\Lambda$ y represent the respective factor loadings of the two indicator variables, $\mathrm{X}$ and $\mathrm{Y} . \delta$ and $\varepsilon$ are the measurement errors of extrinsic dominant variables. $\xi$ and $\eta$ are the respective externally derived latent variables 
and internally derived latent variables. The SEM measurement model assumes that no covariant relationship or causality path exist between latent variables (common factors) and measurement errors.

$$
\eta=B \eta+\Gamma \xi+\zeta
$$

where $B$ represents a structure coefficient matrix that reflects the mutual influences among constituent elements of the endogenous potential variable $\eta$ in the structural model. $\Gamma$ represents a structure coefficient matrix that reflects the effect of the exogenous variable $\xi$ on $\eta$ in the structural model. $\zeta$ represents the residual matrix in the structural model.

\subsection{Parameter Estimation Methods}

The most widely used estimation model is the ML method, followed by the GLS method. With regards to the relationship between estimation methods and sample size, $\mathrm{Hu}$ (1992) found that when sample data follow a normal distribution, the sample size when ML and scaled ML methods are used should be greater than 500 . If the sample size is less than 500 , better results will be obtained if the GLS method is employed for estimation [34]. The Chi-squared test can only be used reasonably when the sample is large and the hypothesis observation data follow a multivariate normal distribution. At this time, the ML estimation method is the most suitable. If the data have a large sample size but the observation data do not follow a multivariate normal distribution, then it is best to employ the GLS estimation method. The number of prefectural-level cities in this study was 283 , which is lower than 500 and the data do not strictly follow a normal distribution. In order to obtain good results, we employed the GLS estimation method in this paper.

\subsection{Indicator Selection and Model Construction}

\subsubsection{Indicator Selection and Data Sources}

The study by Baldwin (1989) pointed out that the sample size should be greater than 200 if researchers want to further execute a model specification search after SEM analysis [34]. In this paper, relevant statistical data of Chinese prefectural-level cities in 2005 and 2015 were taken as sample data. Missing values were removed. Finally, we obtained valid data from 283 prefectural-level cities. Table 1 shows the variables and measurement markers involved in the model. The year 2005 is the last year of the 10th Five-Year Plan of China and is also a transitional year when China entered the 11th Five-Year Plan. In the 11th Five-Year Plan, China first proposed constraint indicators to conserve energy and reduce emissions. This means that China started to enter a phase of strict pollution control and environmental protection from 2006 onwards. Therefore, this paper selected 2005 as the starting point for this study and the year at the end of the 12th Five-Year Plan (2015) as the ending point to analyze changes in environmental pollution impact paths due to economic growth.

(1) Air pollution emission indicators

Since the 1978 Chinese economic reform, the development of China's economy has been mainly driven by rapid industrialization. Although industrialization has occurred for nearly 40 years, industries are still one of the most important growth engines of the Chinese economy. Air pollutants produced by extensive industrialization remain a major source of pollution in China and mainly include sulfur dioxide, nitrogen oxides and particulate matter. In 2015, industrial sulfur dioxide emissions accounted for $83.70 \%$ of total sulfur dioxide emissions, industrial smoke and dust emissions accounted for $80.10 \%$ of total smoke and dust emissions and industrial emissions of nitrogen oxides accounted for $63.80 \%$ of total emissions of nitrogen oxides. Therefore, industrial pollutant emissions are still currently the most important component of air pollutants in China. Therefore, this paper selected industrial emissions as a marker for air pollutants. In addition, due to limitations in data availability, we only selected industrial sulfur dioxide and smoke and dust emissions from 283 prefectural-level cities as air pollutant indicators for analysis. 
(2) Industrial structure indicators

Existing studies show that China is still in the middle stage of industrialization and some parts of China are still in the early stages of industrialization. As main carriers of industries, the development of Chinese prefectural-level cities accompanies industrialization. Therefore, the ratio of industry value added to GDP was used as an industrial structure indicator.

(3) Technical progress indicators

We used the ratio of scientific and technological expenditure to public expenditure as a measure of technical progress.

(4) Environmental regulation indicators

Due to limitations of data availability, the "China City Statistical Yearbook" did not calculate the environmental protection input. Therefore, we constructed an environmental regulation index in this study. The environmental regulation index was calculated from the weighted average of the sulfur dioxide emission reduction rate, industrial smoke and dust emission reduction rate, general industrial solid waste utilization rate and wastewater centralized treatment rate. This index covers three areas of environmental management, namely, air pollution management, industrial solid waste management and wastewater management, which is more comprehensive than investments in environmental pollution management.

The data required for the above indicators were derived from the "China City Statistical Yearbook" (2006) and (2016). Z-score standardization was carried out on all data using SPSS software before structural equation modeling.

Table 1. List of variables used in structural equation modeling.

\begin{tabular}{cc}
\hline Latent Variable & Measurement Index \\
\hline pollutants emission & Industrial sulfur dioxide emission, Industrial smoke and dust emission \\
Economic growth & Per capita GDP \\
Industrial structure & Industrial added value as a proportion of GDP \\
Technical progress & The proportion of expenditure of science and technology accounts for public \\
& financial expenditure \\
Environmental regulation & $\begin{array}{c}\text { Environmental control index calculated by using sulfur dioxide emission } \\
\text { reduction rate, emission reduction rate of industrial smoke and dust, } \\
\text { comprehensive utilization ratio of general industrial solid waste and } \\
\text { centralized treatment rate of sewage }\end{array}$ \\
\hline
\end{tabular}

\subsubsection{Theoretical Hypothesis}

This paper proposes a hypothetical model as shown in Figure 1. Figure 1 shows the path hypotheses that we constructed where economic development levels directly affect pollutants emission and indirectly affect pollutants emission through technical progress, environmental regulation and industrial structure and environmental regulation affects pollutants in reverse through industrial structure and technical progress.

We proposed the following hypotheses according to current theories and the topic of this paper:

Hypothesis H1: Economic growth has direct effects on pollutants emission.

Hypothesis H2: The casual chain of economic growth $\rightarrow$ technical progress $\rightarrow$ reduced pollutants emission is present.

Hypothesis H3: The causal chain of economic growth $\rightarrow$ industrial structure $\rightarrow$ increased pollutants emission is present. 
Hypothesis H4: The causal chain of economic growth $\rightarrow$ environmental regulation $\rightarrow$ reduced pollutants emission is present.

Hypothesis H5: The reverse causation effects of the environment are present.

Hypothesis H5.1: The causal chain of environmental regulation $\rightarrow$ technical progress $\rightarrow$ reduced pollutants emission is present.

Hypothesis H5.2: The causal chain of environmental regulation $\rightarrow$ industrial structure $\rightarrow$ reduced pollutants emission is present.

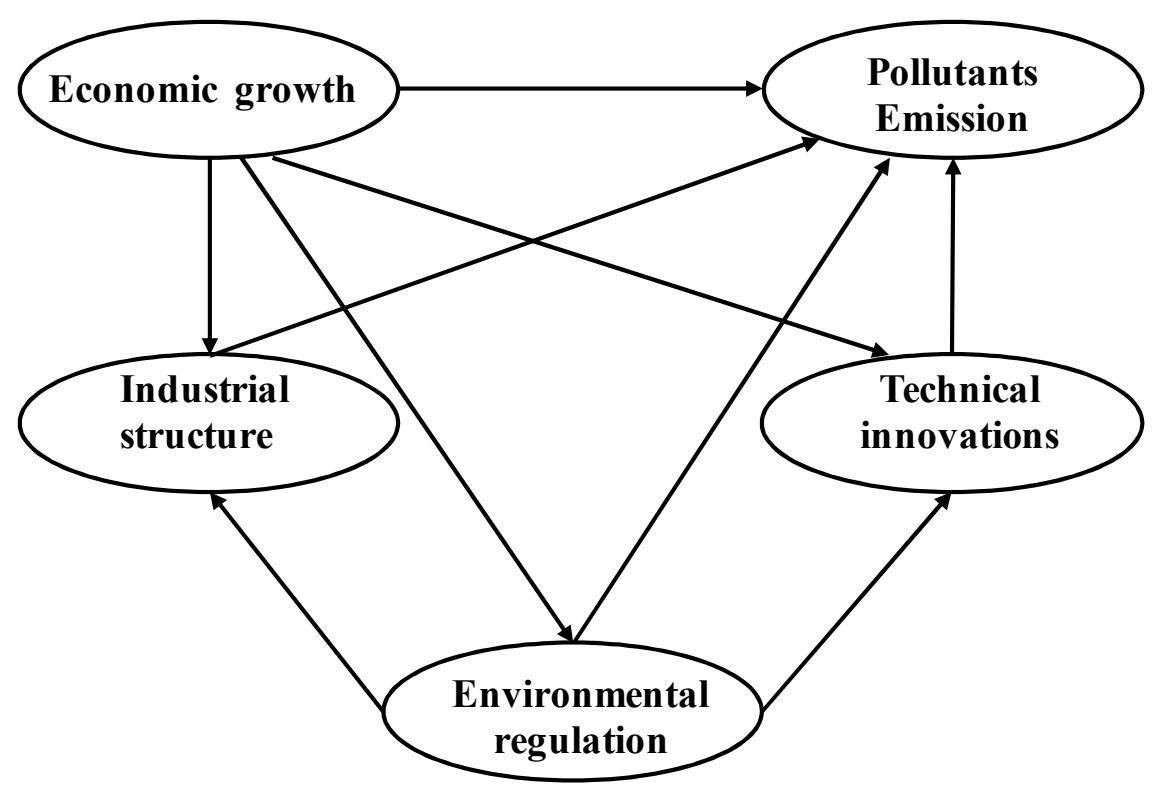

Figure 1. Theoretical hypothetical model of how economic development levels affect pollutants emission.

\section{Results}

AMOS 17.0 software was used to validate the aforementioned hypotheses according to the aforementioned hypothetical relationships.

\subsection{Analysis of Model Goodness-of-Fit}

Tables 2-5 are the test results of model goodness-of-fit. The follow model goodness-of-fit indicators was within an acceptable range, showing that the goodness-of-fit for our 4 constructed path models was good.

Table 2. Model goodness-of-fit of structural path analysis for industrial smoke and dust emission in 2005.

Model absolute fit indices: $\chi^{2}=0.694$, GFI $=0.999>0.900$, AGFI $=0.996>0.90$, RMR $=0.006<0.050$;

Model incremental fit measurement: NFI $=0.996>0.900$, RFI $=0.964>0.900$, IFI $=1.002>0.9$, CFI $=1>0.900$;

Model parsimonious fit measurement: NC value $\left(\chi^{2}\right.$ degree of freedom ratio $)=0.694$.

Table 3. Model goodness-of-fit of structural path analysis for industrial sulfur dioxide emission in 2005.

Model absolute fit indices: $\chi^{2}=694, \mathrm{GFI}=0.999>0.900, \mathrm{AGFI}=0.996>0.900, \mathrm{RMR}=0.006<0.05$;

Model incremental fit measurement: NFI $=0.999>0.900$, RFI $=0.987>0.900$, IFI $=0.998>0.900$, CFI $=1>0.900$;

Model parsimonious fit measurement: NC value $\left(\chi^{2}\right.$ degree of freedom ratio $)=0.694$. 
Table 4. Model goodness-of-fit of structural path analysis for industrial smoke and dust emission in 2015.

Model absolute fit indices: $\chi^{2}=0.316, \mathrm{GFI}=1>0.900, \mathrm{AGFI}=0.993>0.900, \mathrm{RMR}=0.007<0.050$;

Model incremental fit measurement: NFI $=0.999>0.900, \mathrm{RFI}=0.985>0.900, \mathrm{IFI}=0.976>0.900, \mathrm{CFI}=1>0.900$;

Model parsimonious fit measurement: NC value $\left(\chi^{2}\right.$ degree of freedom ratio $)=0.316$.

Table 5. Model goodness-of-fit of structural path analysis for industrial sulfur dioxide emission in 2015.

Model absolute fit indices: $\chi^{2}=0.316$, GFI $=1>0.900$, AGFI $=0.993>0.900$, RMR $=0.007<0.050$;

Model incremental fit measurement: NFI $=0.997>0.900, \mathrm{RFI}=0.968>0.900, \mathrm{IFI}=0.987>0.900, \mathrm{CFI}=1>0.900$;

Model parsimonious fit measurement: NC value $\left(\chi^{2}\right.$ degree of freedom ratio $)=0.316$.

\subsection{Path Analysis of the Effects of Economic Growth on Industrial Smoke and Dust Emissions}

Figures 2 and 3 show the path diagrams of how economic development in prefectural-level cities affected industrial smoke and dust emissions in 2005 and 2015, respectively. For the year 2005, the standardized path coefficient (0.05) for the effects of economic growth on industrial smoke and dust emissions did not pass the significance test and hypothesis $\mathrm{H} 1$ was rejected; the standardized path coefficient (0.37) of the effects of economic growth on technical progress passed the significance test (>99.9\% confidence level). This shows that economic growth had positive promoting effects on technical progress but the effects of technical progress on industrial smoke and dust emissions were not significant (the standardized path coefficient did not pass the significance test) and hypothesis $\mathrm{H} 2$ was rejected. This means that the path where economic growth in prefectural-level cities in China in 2005 affected technical progress to decrease industrial smoke and dust emissions was not true. Economic growth had positive promoting effects on environmental regulation (standardized path coefficient of 0.29 and the significance test was passed). At the same time, environmental regulation had negative inhibitory effects on industrial smoke and dust emissions (standardized path coefficient of -0.15 and the significance test was passed at the $95 \%$ confidence level). The standardized path coefficient of economic growth affecting industrial smoke and dust emissions through environmental regulation was $0.29 \times(-0.15)=-0.044$. This shows that economic growth suppressed industrial smoke and dust emissions through environmental regulation, that is, Hypothesis $\mathrm{H} 4$ was true. Economic growth had positive effects on industrial structure (standardized path coefficient of 0.55 and the significance test was passed). This means that regions with high economic growth had higher levels of industrialization. At the same time, the industrial structure had positive promoting effects on industrial smoke and dust emissions (standardized path coefficient of 0.22 and the significance test was passed). The standardized path coefficient of economic growth affecting industrial smoke and dust emissions through industrial structure was $0.55 \times 0.22=0.121$. This shows that economic growth increased industrial smoke and dust emissions through the industrial structure and Hypothesis $\mathrm{H} 3$ was true. The effects of environmental regulation on industrial structure and technical progress were not significant (standardized path coefficient did not pass the significance tests). This shows that the hypothesis (H5) that environmental regulation affects industrial structure and technical progress in reverse was not true. This means that the reverse causation mechanisms of environmental regulation had not yet formed in Chinese prefectural-level cities in 2005. From the above analysis, we can see that the impact pathway of economic growth in Chinese prefectural-level cities in 2005 with respect to industrial smoke and dust emissions occurred mainly through the two causal chains of economic growth $\rightarrow$ industrial structure $\rightarrow$ increase smoke and dust emissions and economic growth $\rightarrow$ environmental regulation $\rightarrow$ decreased smoke and dust emissions and positive effects were significantly higher than negative effects $(0.121>0.044)$. This shows that industrialization was the main cause of smoke and dust emissions in prefectural-level cities in China in 2005. Although environmental regulation can inhibit emissions to some extent, its effects cannot reduce the positive stimulatory effects of industrialization. 
With regards to the paths on how economic development levels affect smoke and dust emissions in 2005 (Figure 3), hypotheses H1 and H3 were found to be true while H2 and H4 were rejected. Economic development levels showed a positive correlation with smoke and dust emissions at the $95 \%$ confidence interval and the standardized path coefficient for economic development levels affecting smoke and dust emissions was 0.06 . On the other hand, environmental regulation has strong effects on smoke and dust emissions, as environmental regulation showed a significant negative correlation with smoke and dust emissions at the $99.9 \%$ confidence interval and its standardized effector coefficient was -0.94 . Evidently, the reduction in smoke and dust emissions was due to the effects of environmental regulation. The effects of industrial structure and technical progress on smoke and dust emissions did not pass significance testing, showing that these effects were not significant. The overall effects of economic development levels on smoke and dust emissions were composed of direct effects of economic growth on smoke and dust emissions and indirect effects of the causal chain of economic growth $\rightarrow$ environmental regulation $\rightarrow$ reduced environmental pollution and the overall effect was $0.06+0.02 \times(-0.94)=0.041$. From this we can see that due to the effects of environmental regulation, the scale effects of economic development on smoke and dust emissions were inhibited, resulting in no large increases in smoke and dust emissions when economic development levels increased. The effects of environmental regulation on industrial structure and technical progress did not pass the significance tests. This shows that the reverse causation mechanism acting on industrial structure and technical progress to decrease smoke and dust emissions, that is, Hypothesis H5, was not true. The reduction in smoke and dust emissions is mainly dependent on an investment in the use of end-treatment equipment for smoke and dust. This does not require large technical support or transformation in the industrial structure. However, from a long-term perspective, technical and structural effects are still required to solve the problem of smoke and dust emissions from the root (source). This can be achieved by strengthening technical progress, accelerating the transformation of the industrial structure, achieving clean production and implementing management options at the source.

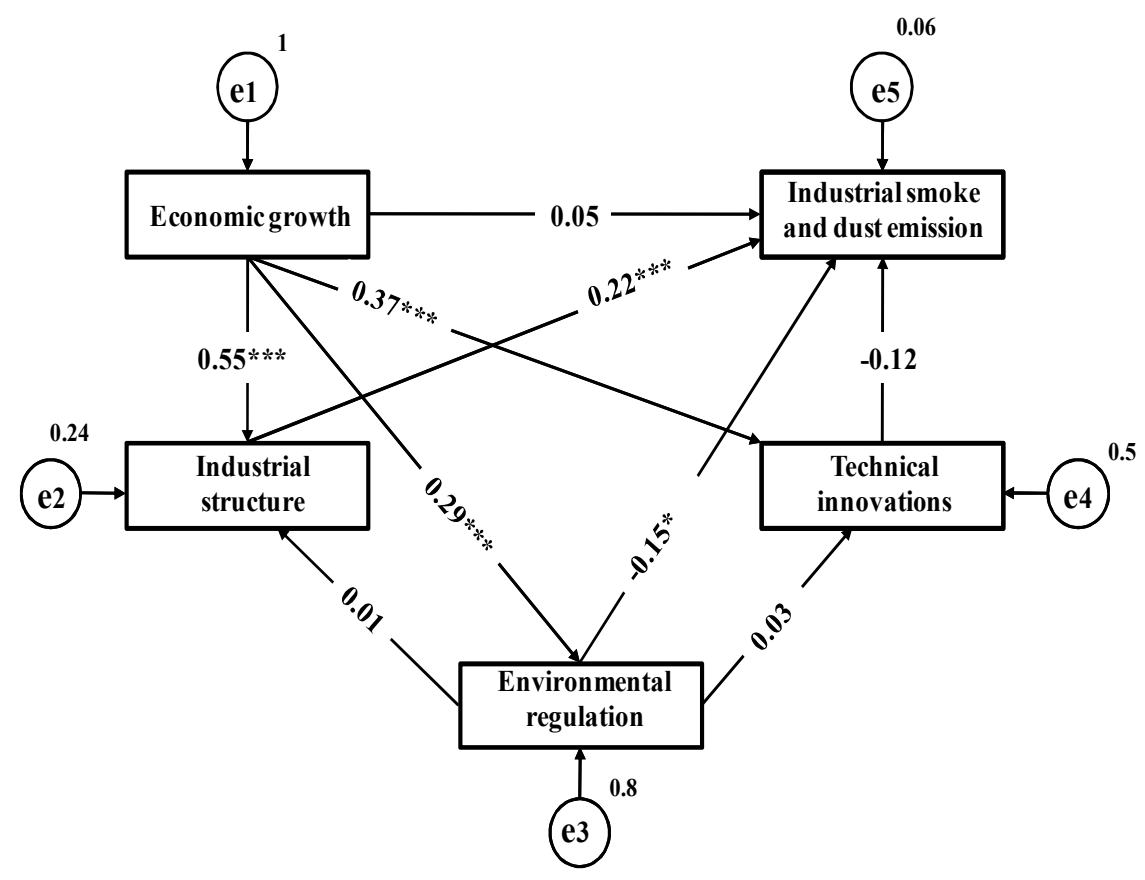

Figure 2. Path diagram of how economic growth in 2005 affected industrial smoke and dust emission. (Note: ${ }^{*}, * *, * * *$ indicate significance at the $0.05,0.01$ and 0.001 levels, respectively and the fitting result is significant.) 


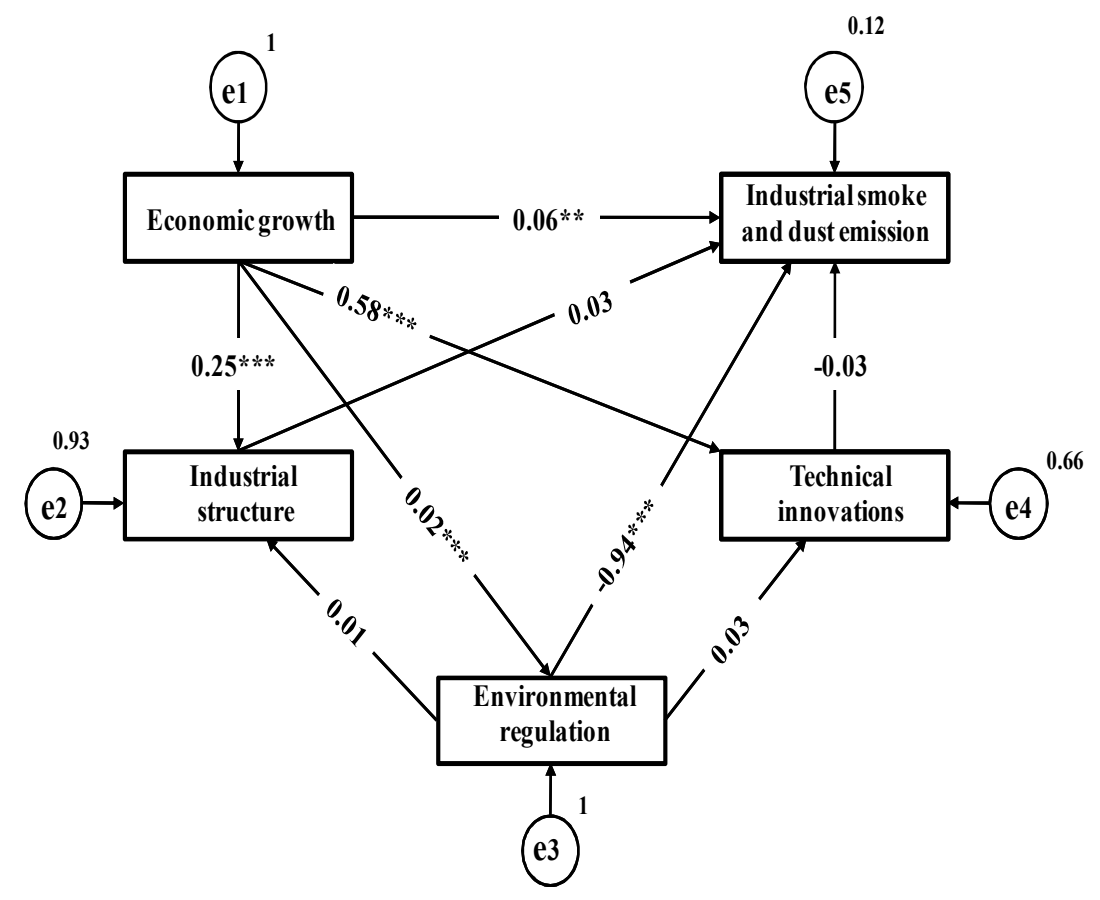

Figure 3. Path diagram of how economic growth in 2015 affected industrial smoke and dust emission. (Note: ${ }^{*}, * *, * *$ indicate significance at the $0.05,0.01$ and 0.001 levels, respectively and the fitting result is significant.)

\subsection{Path Analysis of the Effects of Economic Growth on Industrial Sulfur Dioxide Emissions}

Figures 4 and 5 show the path diagrams of how economic development in prefectural-level cities affected industrial sulfur dioxide emissions in 2005 and 2015, respectively. From Figure 4, we can see that in 2005, economic growth had positive promoting effects on industrial sulfur dioxide emissions (standardized path coefficient of 0.18 and the significance test was passed at the $95 \%$ confidence level), that is Hypothesis H1 was true. The hypothesis (H2) that economic growth inhibits sulfur dioxide emissions through technical progress was found to be not true. Economic growth had inhibitory effects on industrial sulfur dioxide emissions through environmental regulation (standardized indirect path coefficient was $0.29 \times-0.01=-0.003$ ) and hypothesis $\mathrm{H} 4$ was found to be true but its effects were not large. Economic growth had positive promoting effects on sulfur dioxide emissions through the industrial structure (standardized indirect path coefficient was $0.55 \times 0.18=0.099$ ) and hypothesis H3 was found to be true. This means that economic growth increased industrial sulfur dioxide emissions by promoting industrialization. The hypothesis (H5) of the reverse causation mechanisms of environmental regulation was found to be not true.

The positive effects of economic growth on industrial sulfur dioxide emissions increased in 2015 (Figure 5) (standardized path coefficient of 0.35 and significant at the 0.01 level, that is, higher than the standardized path coefficient in 2005). Economic growth had inhibitory effects on industrial sulfur dioxide emissions through technical progress, with a standardized indirect effect path coefficient of $0.58 \times-0.15=-0.087$. Economic growth had positive effects on sulfur dioxide emissions through the industrial structure (Hypothesis $\mathrm{H} 3$ was true) and the standardized indirect effect path coefficient was $0.25 \times 0.11=0.028$. Hypotheses $\mathrm{H} 4$ and $\mathrm{H} 5$ were not true in 2015 . From the path diagram, we can see that economic growth levels and industrial structure had some positive effects on industrial sulfur dioxide emissions. Economic growth in Chinese cities that is driven by urbanization greatly facilitates the investment of large amounts of resources and the emission of large amounts of pollutants. Although the current industrial structure is still in a transformation phase, industrial sulfur dioxide emissions have increased instead of decreased. This shows that in China, industry still dominates and 
inside the industrial structure, the production and supply of electricity and heat are still important foundational support industries that determine the amount of industrial sulfur dioxide emissions. Although technical progress has resulted in some reduction in industrial sulfur dioxide emissions, its effect strength is not great. With regards to industrial sulfur dioxide emissions, emission reduction and reverse causation mechanisms due to environmental regulations were not formed. Sulfur dioxide emissions at the source and end can only be controlled by reducing sulfur dioxide emissions, accelerating the transformation of the internal industrial structure, increasing expenditure in science and technology research and strengthening environmental regulations and the formulation of sulfur dioxide emission standards for relevant industries.

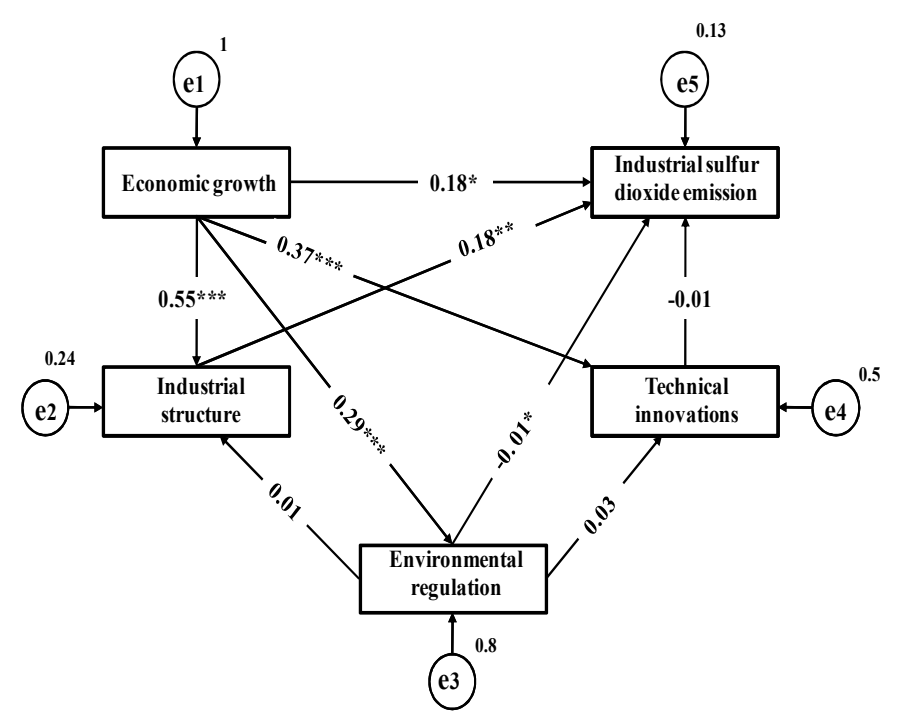

Figure 4. Path diagram of how economic growth in 2005 affected industrial sulfur dioxide emission. (Note: ${ }^{*}, * *, * *$ indicate significance at the $0.05,0.01$ and 0.001 levels, respectively and the fitting result is significant.)

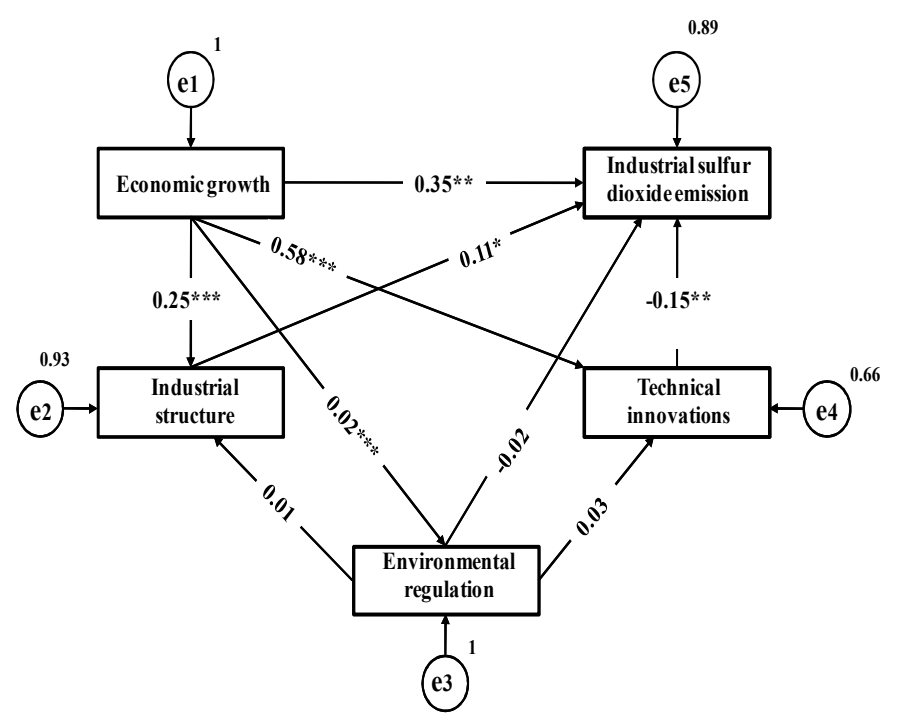

Figure 5. Path diagram of how economic growth in 2015 affected industrial sulfur dioxide emissions (Note: ${ }^{*}, * *, * *$ indicate significance at the $0.05,0.01$ and 0.001 levels, respectively and the fitting result is significant.) 


\subsection{Evolution of Impact Paths}

We designed 5 major paths in this study: the direct impact path of economic growth on environmental pollutant emission, the indirect impact path of economic growth affecting emission through the industrial structure, technical progress and environmental regulations and the reverse causation path of environmental regulations affecting the amount of emission through industrial structure and technical progress (Table 6). Since 2005 when China first included the goal of energy conservation and emission reduction in its 5-year plans, the impact path strength of economic growth in prefectural-level cities in China with respect to smoke and dust emissions and industrial sulfur dioxide emission increased. This shows that negative environmental externalities due to economic growth of prefectural-level cities still exist and are becoming more significant. The positive indirect effects of economic growth on the amount of emission through the industrial structure have decreased. In 2015, its effects on industrial smoke and dust emissions disappeared. This means that the industrial structure is no longer the primary influential factor of industrial smoke and dust emissions. With regards to sulfur dioxide, although its positive effects have decreased, the industrial structure is the only path that affects the survival of this path. This shows that the industrial structure is still a primary influential factor in Chinese prefectural-level cities. Summarizing the above two paths (increased economic growth impact path and weakened industrial structure impact path), we can see that besides the industrial structure, other factors can also affect the emission of industrial pollutants in prefectural-level cities in China, such as system factors, spatial migration of industries and so forth. This is because economic growth itself cannot result in the emission of pollutants and its impact path should be a series of market behavior (scale expansion) and policy behavior (spatial migration of industries caused by policies) that affect the increase or decrease in the emission of pollutants once a certain economic growth level has been reached.

Economic growth only produces negative effects on industrial sulfur dioxide emissions through technical progress and the effect strength is increased. This shows that technical progress was the most important path for the reduction of sulfur dioxide emissions in prefectural-level cities in the past decade. As for emissions reduction in China, cleaner technology development plays a crucial role [35]. Cleaner technology solutions involve radical innovations that leapfrog standard routines and knowledge and also requires the creation of new infrastructures for companies and new levels of functionality to customers, especially for the capital and natural resource intensive industries which is also the main source of pollution [36,37].

Table 6. Path evolution of effects of economic growth in Chinese cities on the emissions of air pollutants.

\begin{tabular}{|c|c|c|c|c|c|c|}
\hline \multirow[t]{2}{*}{ Influence Path } & \multicolumn{3}{|c|}{$\begin{array}{l}\text { Industrial Smoke and Dust } \\
\text { Emissions }\end{array}$} & \multicolumn{3}{|c|}{$\begin{array}{l}\text { Industrial Sulfur Dioxide } \\
\text { Emissions }\end{array}$} \\
\hline & 2005 & 2015 & 2015-2005 & 2005 & 2015 & 2015-2005 \\
\hline Economic growth $\rightarrow$ Emissions & None & Forward & Strengthen & Forward & Forward & Strengthen \\
\hline $\begin{array}{l}\text { Economic growth } \rightarrow \text { Industrial } \\
\text { structure } \rightarrow \text { Emissions }\end{array}$ & Forward & None & Disappear & Forward & Forward & Decreased \\
\hline $\begin{array}{l}\text { Economic growth } \rightarrow \text { Technical } \\
\text { progress } \rightarrow \text { Emissions }\end{array}$ & None & None & None & None & Negative & Strengthen \\
\hline $\begin{array}{l}\text { Economic growth } \rightarrow \text { Environmental } \\
\text { regulation } \rightarrow \text { Emissions }\end{array}$ & Negative & Negative & Decreased & Negative & None & Decreased \\
\hline $\begin{array}{l}\text { Environmental regulation } \rightarrow \text { Industrial } \\
\text { structure } \rightarrow \text { Emissions }\end{array}$ & None & None & None & None & None & None \\
\hline $\begin{array}{l}\text { Environmental regulation } \rightarrow \text { Technical } \\
\text { progress } \rightarrow \text { Emissions }\end{array}$ & None & None & None & None & None & None \\
\hline
\end{tabular}

The negative and indirect effects of economic growth on the amount of emissions through environmental regulations were found to be weakened. In 2015, the inhibitory effect of environmental regulation on industrial sulfur dioxide emissions had disappeared. This means that the emission reduction effects of environmental regulations on the emissions of the two types of pollutants had 
started to weaken. We can also interpret this as the environmental regulatory measures or policies on the two types of pollutants exhibiting a weakening trend. In addition, our study results showed that the reverse causation mechanisms of environmental regulations were not present in the two periods.

\section{Discussion and Conclusions}

The empirical relationship between economic growth and pollutants emission (such as the EKC curve) has important significance for understanding pollutants emission during economic growth and the variation patterns of its resulting environmental impact. However, empirical relationships can only provide information on environmental characteristics at different development phases and have limited use for the formulation of targeted environmental policies. In addition, numerous existing study results also show that different types of pollutions exhibit different characteristics in the empirical relationship between economic growth and pollutants emission. Although a large number of empirical studies have been searching for general laws, no consensus has been achieved thus far. An in-depth understanding of the impact paths of economic growth on the environment is required in order to formulate effective emission reduction policies. This study used the theoretical understanding of the relationship between economic growth and pollutants emission as a basis and employed structural equation modeling using 283 prefectural-level cities in China in 2005 and 2015 as study samples to analyze the impact paths of economic growth on industrial smoke and dust and sulfur dioxide emissions.

The results showed that for different pollutants, the impact paths of economic growth on their emission showed both similarities and differences. First, with regards to industrial smoke and dust emissions and sulfur dioxide emissions, the effects of economic growth on the amount of these two emissions through environmental regulations and the industrial structure were negative inhibitory effects and positive promoting effects, respectively. This means that in prefectural-level cities in China, environment regulation factors have produced some effects in reducing the emissions of these two pollutants while the industrial structure (level of industrialization) can increase the emissions of these two pollutants. These impacts of industrial structure and environmental regulation on $\mathrm{SO}_{2}$ are also supported by other research [27]. However, the effect strength of these two paths shows a gradual weakening. It should be noticed that the study only considered the factor of industrialization level (shares of secondary industries to total GDP) which merely is one of the composition factors affect pollution emission. As mentioned by Dina S. (2004), with economic development, the economic structural changes from rural to urban or the agricultural to the industrial accompany another structural change, from energy intensive industry to services and knowledge-based technology intensive industry [18], which was not considered in this study.

Second, these two paths differ in effect strength and its changes. The positive promoting effects of the industrial structure on pollutant emission are significantly higher than the inhibitory effects of environmental regulation. With regards to the impact path of economic growth $\rightarrow$ environmental regulations $\rightarrow$ amount of emissions, the strength of the inhibitory effects of economic growth on industrial smoke and dust emissions in 2005-2015 weakened while the inhibitory effects of this path on industrial sulfur dioxide emissions disappeared by 2015. This shows that the effects of current environmental regulation measures or policies exhibit a weakening trend. Conversely, the impact path of economic growth $\rightarrow$ industrial structure $\rightarrow$ amount of emissions was the reverse of the above path. This means that the effects of the industrial structure on industrial sulfur dioxide emissions have weakened and its effects on industrial smoke and dust emissions have disappeared.

Third, the economic growth only produces inhibitory effects on industrial $\mathrm{SO}_{2}$ emission through technical innovation but has no effects on industrial smoke and dust emissions. The above analysis also showed that the impact paths of economic growth on pollutant emission vary for different pollutants. The current studies suggest that the wealthy countries can afford to invest in incremental and radical technological innovation [38]. Technological progress leads to greater efficiency in the use of energy and materials. Thus, this progress can reduce the emission from the very beginning of production 
through reuse and recycling of by-products and materials. Such as, the recycling of $\mathrm{SO}_{2}$ in nonferrous metal processing. This finding can also explain why currently, a consistent conclusion on the empirical relationship between economic growth and environmental pollution is difficult to obtain in academia. Therefore, localized studies on specific pollutants and specific regions should be carried out in order to formulate targeted environmental policies.

In addition, our study also found that the direct impact path of economic growth on environmental pollution also passed significance testing, particularly in 2015. This shows that other reasons affect pollutant emission, such as international trade [39], urbanization [40], consumption pattern transformation [41] and so forth. Economic growth itself cannot result in the emission of pollutants and its impact path should be a series of market behavior (scale expansion) and policy behavior (spatial migration of industries caused by policies) that affect the increase or decrease in emission of pollutants once a certain economic growth level has been reached. This is also a shortcoming of this study and there is an urgent need to carry out corresponding empirical studies. In addition, although we attempted to examine the impact paths of economic growth on environmental pollution in prefectural-level cities in China, due to data availability and data quality limitations, we only included 283 prefectural-level cities as study samples. The coverage of spatial samples is not comprehensive and the type of pollutants is also not complete. Therefore, the study results can only be limited to the explanation of the impact paths of two time points and 283 prefectural-level cities and this is the greatest limitation of this study. In the future, panel data should be used for the examination of impact paths, the study period should be extended and the distribution of spatial samples should be more comprehensive. This will require higher quality data as support. We believe that as China's statistical system improves, future corresponding research work will become more convenient and more universal conclusions can be obtained, which can be used to guide policy implementation.

Author Contributions: Conceptualization, Z.Z. and B.X.; Methodology, N.Y. and Z.Z.; Software, N.Y. and C.L.; Data Curation, J.M.; Writing-Original Draft Preparation, N.Y. and Z.Z.; Writing-Review \& Editing, B.X. and X.C.; Supervision, Z.Z.

Funding: This research was funded by Natural Science Foundation of China (41301652, 41471116 and 41561110), the Fundamental Research Funds for the Central Universities (lzujbky-2018-137), Belt and Road Special Project of Lanzhou University (20181dbryb018).

Acknowledgments: We would like to acknowledge the anonymous reviewers for their valuable comments.

Conflicts of Interest: The authors declare no conflict of interest.

\section{References}

1. Cost of Pollution in China: Economic Estimates of Physical Damages, 2007. World Bank Website. Available online: http:/ / www.worldbank.org/ (accessed on 15 June 2018).

2. Global Energy Network Institute (GENI); Meisen, P.; Hawkins, S. Renewable Energy Potential of China: Making the Transition from Coal-Fired Generation; Publisher: San Diego, CA, USA, 2009.

3. Circular of the State Council on the Issuance of the Comprehensive Work Plan on Energy Saving and Emission Reduction in the Thirteenth Five-Year Plan, 2016. The Chinese Government Website. Available online: http: //www.gov.cn/zhengce/content/2017-01/05/content_5156789.htm (accessed on 15 June 2018). (In Chinese)

4. National Bureau of Economic Research; Grossman, G.M.; Krueger, A.B. Environmental Impacts of a North American Trade Agreement; Publisher: Cambridge, MA, USA, 1991; Volume 3914.

5. Huang, B.L.; Xie, S.X. Economic growth, the way of FDI and emissions of $\mathrm{SO}_{2}$ in China: An analysis on Chinese provincial panel data 2003-2009. World Econ. Stud. 2012, 4, 64-70. (In Chinese)

6. Shi, Y.; Xia, Y.F.; Lu, B.H.; Liu, N.; Zhang, L.; Li, S.J.; Wei, L. Emission inventory and trends of NOx for China, 2000-2020. J. Zhejiang Univ. Sci. 2014, 15, 454-464. (In Chinese) [CrossRef]

7. Li, C.J.; Pan, C.Z.; Lei, H.J.; Tian, P. Decomposing analysis on China's industrial wastewater discharges in 1992-2008. Res. Environ. Sci. 2013, 26, 569-575. (In Chinese)

8. He, J.; Richard, P. Environmental kuznets curve for $\mathrm{CO}_{2}$ in Canada. Ecol. Econ. 2010, 69, 1083-1093. [CrossRef] 
9. Yan, D.; Lei, Y.L.; Shi, Y.K.; Zhu, Q.; Li, L.; Zhang, Z.E. Evolution of the spatiotemporal pattern of PM2.5 concentrations in China-A case study from the Beijing-Tianjin-Hebei region. Atmos. Environ. 2018, 183, 225-233. [CrossRef]

10. Wang, Y.; Kang, Y.L.; Wu, X.Q.; Xiao, Y. Estimating the environmental Kuznets curve for ecological footprint at the global level: A spatial econometric approach. Ecol. Indicat. 2013, 34, 15-21. [CrossRef]

11. Bagliani, M.; Bravo, G.; Dalmazzone, S. A consumption-based approach to environmental Kuznets curves using the ecological footprint indicator. Ecol. Econ. 2008, 65, 650-661. [CrossRef]

12. Managi, S.; Jena, P.R. Environmental productivity and Kuznets curve in India. Ecol. Econ. 2008, 65, 432-440. [CrossRef]

13. Halkos, G.E.; Tzeremes, N.G. Exploring/the existence of Kuznets curve in countries' environmental efficiency using DEA window analysis. Ecol. Econ. 2009, 68, 2168-2176. [CrossRef]

14. Bimonte, S.; Stabile, A. Land consumption and income in Italy: A case of inverted EKC. Ecol. Econ. 2017, 131, 36-43. [CrossRef]

15. Dong, B.; Zhang, M.; Mu, H.L.; Su, X.M. Study on decoupling analysis between energy consumption and economic growth in Liaoning province. Energy Pol. 2016, 97, 414-420. [CrossRef]

16. Yang, Y.C.; Liu, J.H.; Zhang, Y.T. An analysis of the implications of China's urbanization policy for economic growth and energy consumption. J. Clean. Prod. 2017, 161, 1251-1262. [CrossRef]

17. Sun, S.; Fang, C.L. Water use trend analysis: A non-parametric method for the environmental Kuznets curve detection. J. Clean. Prod. 2018, 172, 497-507. [CrossRef]

18. Dinda, S. Environmental Kuznets curve hypothesis: A survey. Ecol. Econ. 2004, 49, 431-455. [CrossRef]

19. Webber, D.J.; Allen, D.O. Environmental Kuznets curves: Mess or meaning? Int. J. Sustain. Dev. Plan. 2010, 17, 198-207. [CrossRef]

20. Gill, A.R.; Viswanathan, K.K.; Hassan, S. The environmental Kuznets Curve (EKC) and the environmental problem of the day. Renew. Sustain. Energy Rev. 2018, 81, 1636-1642. [CrossRef]

21. Ali, W.; Abdullah, A.; Azam, M. Re-visiting the environmental Kuznets curve hypothesis for Malaysia: Fresh evidence from ARDL bounds testing approach. Renew. Sustain. Energy Rev. 2017, 77, 990-1000. [CrossRef]

22. Kijima, M.; Nishide, K.; Ohyama, A. Economic models for the environmental Kuznets curve: A survey. J. Econ. Dyn. Control 2010, 34, 1187-1201. [CrossRef]

23. Azimi, M.; Feng, F.; Yang, Y. Air pollution inequality and its sources in $\mathrm{SO}_{2}$ and $\mathrm{NO}_{\mathrm{x}}$ emissions among Chinese provinces from 2006 to 2015. Sustainability 2018, 10, 25. [CrossRef]

24. Shen, J.Y. A simultaneous estimation of environmental Kuznets curve: Evidence from China. China Econ. Rev. 2006, 17, 383-394. [CrossRef]

25. Huang, J.T. Sulfur dioxide $\left(\mathrm{SO}_{2}\right)$ emissions and government spending on environmental protection in China-Evidence from spatial econometric analysis. J. Clean. Prod. 2018, 175, 431-441. [CrossRef]

26. Lee, S.; Oh, D.W. Economic growth and the environment in China: Empirical evidence using prefecture level data. China Econ. Rev. 2015, 36, 73-85. [CrossRef]

27. Liu, Q.Q.; Wang, S.J.; Zhang, W.Z.; Zhan, D.S.; Li, J.M. Does foreign direct investment affect environmental pollution in China's cities? A spatial econometric perspective. Sci. Total Environ. 2018, 613, 521-529. [CrossRef] [PubMed]

28. Zhu, L.; Gan, Q.M.; Liu, Y.; Yan, Z.J. The impact of foreign direct investment on $\mathrm{SO}_{2}$ emissions in the Beijing-Tianjin-Hebei region: A spatial econometric analysis. J. Clean. Prod. 2017, 166, 189-196. [CrossRef]

29. Zhu, Z.Q.; Liu, Y.; Tian, X.; Wang, Y.F.; Zhang, Y. $\mathrm{CO}_{2}$ emissions from the industrialization and urbanization processes in the manufacturing center Tianjin in China. J. Clean. Prod. 2017, 168, 867-875. [CrossRef]

30. $\mathrm{Xu}, \mathrm{T}$. Investigating environmental Kuznets curve in China-Aggregation bias and policy implications. Energy Pol. 2018, 114, 315-322. [CrossRef]

31. Yang, X.J.; Li, M.F.; Wang, R.; Gu, J.Z. Review on empirical research of research of relationship between environmental pollution and economic development. Environ. Sci. Manag. 2016, 41, 53-58. (In Chinese)

32. Wu, M.L. Structural Equation Model Operation and Application of AMOS; Chongqing University Press: Chongqing, China, 2010; Volume 1, p. 280. (In Chinese)

33. Hou, J.T.; Wen, Z.L.; Cheng, Z.J. Structural Equation Model and Its Application; Education Science Press: Beijing, China, 2004; pp. 1-3. (In Chinese)

34. Bentler, P.M.; Hu, L.T.; Kano, Y. Can test statistics in covariance structure analysis be trusted? Psychol. Bull. 1992, 112, 351-362. (In Chinese) 
35. Zheng, S.Q.; Kahn, M.E. A new era of pollution progress in urban China? J. Econ. Perspect. 2017, 31, 71-92. [CrossRef]

36. Bhupendra, K.V.; Sangle, S. What drives successful implementation of pollution prevention and cleaner technology strategy? The role of innovative capability. J. Environ. Manag. 2015, 155, 184-192. [CrossRef] [PubMed]

37. Cristina De Stefano, M.; Montes-Sancho, M.J.; Busch, T. A natural resource-based view of climate change: Innovation challenges in the automobile industry. J. Clean. Prod. 2016, 139, 1436-1448. [CrossRef]

38. Ginevicius, R.; Lapinskiene, G.; Peleckis, K. The evolution of the environmental Kuznets curve concept: The review of the research. Panoeconomicus 2017, 64, 93-112. [CrossRef]

39. Cole, M.A. Development, trade and the environment: How robust is the Environmental Kuznets Curve? Environ. Dev. Econ. 2003, 8, 557-580. [CrossRef]

40. Han, L.; Zhou, W.; Li, W.; Li, L. Impact of urbanization level on urban air quality: A case of fine particles (PM2.5) in Chinese cities. Environ. Pollut. 2014, 194, 163-170. [CrossRef] [PubMed]

41. Lorek, S.; Spangenberg, J.H. Sustainable consumption within a sustainable economy-Beyond green growth and green economies. J. Clean. Prod. 2014, 63, 33-44. [CrossRef]

(C) 2018 by the authors. Licensee MDPI, Basel, Switzerland. This article is an open access article distributed under the terms and conditions of the Creative Commons Attribution (CC BY) license (http:/ / creativecommons.org/licenses/by/4.0/). 